\title{
The Stress Characteristics of Numerical Analysis on Bridge Pile Founda- tion in High and Steep Rock Slopes
}

\author{
He Zhongming ${ }^{1,2, *}$, Liu Senzhi ${ }^{2}$, Wu Tao ${ }^{3}$ and Deng $\mathrm{Xi}^{2}$
}

${ }^{I}$ Key Laboratory of Bridge Engineering Safety Control by Hunan Province, Department of Education (Changsha University of Science \& Technology), Changsha, 410114, P.R. China; ${ }^{2}$ School of Communication and Transportation Engineering, Changsha University of Science and Technology, Changsha 410114, P.R. China, ${ }^{3}$ School of Civil Engineering and Architecture, Changsha University of Science and Technology, Changsha 410114, P.R. China

\begin{abstract}
The bearing mechanism of bridge pile foundation in high-steep rock slopes is much more complex than that in the flat. In the basis of theory research and model experiment made by previous scholars, then the software of finite element method is used on numerical analysis in this paper, which systematically discusses the distribution of body force of pile, the displacement in pile top and situation of pile's thrusting force distribution caused by the soil (rock) around the pile under the combined load, the negative impact of combined load on pile stability was also discussed, which can guide engineering practice.
\end{abstract}

Keywords: Bridge pile foundation, combined load, high - steep rock slopes, finite element method.

\section{INTRODUCTION}

With the rapid development of national economy and the implementation of western development strategy, the construction of the railway and highway traffic engineering infrastructure in the west of China is entering comprehensively promote stage. In the western and mountainous area, high and steep mountains, thick wood, complex topography and the river which runoff various regions were very common. When the line of highway had to through these regions, in order to satisfied the highway design and avoid environmental damage, the bridge may well used as high grade highway which along the high and steep rock slope, across the river or declivity. In this way, the bridge pile foundation was built directly on the adverse geological condition such as high steep rock slope [1].

Domestic and overseas scholars have made a lot of study about stress characteristics on the bridge piles in rock slope, then achieved many proudly research results [2-7], M. H. Zhao et al. concluded that the landslide thrust of rock slope distributed as parabola by the in - situ test, and then deduced the finite difference numerical solution that suitable for the calculation of internal force and displacement of bridge pile foundation in high steep slope; based on the flexure differential equation of pile foundation under the vertical load, by means of equation analysis calculated similar criterion and based on this theory, launch the indoor model test. At the moment, the research of bridge pile foundation on high-steep rock slope mostly focused on the theory and model experiment, only a small number of scholars made numerical simulation through the finite element method. Besides, most of the existing specification and experiment are aimed at the ground pile foundation, doesn't take into account the particularity of high-steep rock slope pile foundation, which it may brings a certain of hidden danger to engineering practices. Therefore, the soft of finite element method used to numerical analysis in this paper, by changing the value of vertical load that acting on the pile top and slope top, author systematically discusses the body force's distribution of pile, the displacement in pile top and situation of pile's thrusting force distribution made by the soil (rock) around the pile under the combined load, by changing the combination method of load to analysis the negative impact of combined load on pile stability. All the above we made will put forward guidance to engineering practice.

\section{ANALYSIS AND COMPARISON OF PILE FOUN- DATION STRESS}

Compared with the pile foundation in the flat, the bearing mechanism of bridge pile foundation in high-steep rock slopes is much more complex. The stress pattern of former is that: pile foundation acting on an environment which can be saw perfectly symmetry, bearing the external force from pile top (such as vertical load, horizontal load and eccentric bending moment, etc.), so the pile body is compressed, produce a downward displacement relative to the soil (rock) around the pile, the soil (rock) around the pile provide the upward side friction to it. When the external force of pile top continuously increasing until maximum, it is that the upward side friction achieve the maximum. Support force provided by the soil (rock) at the terminal of pile, which is the pile's terminal resistance, beginning play a role. It balance with the friction of the other side. The pile in ground stress state is shown in Fig. (1). 


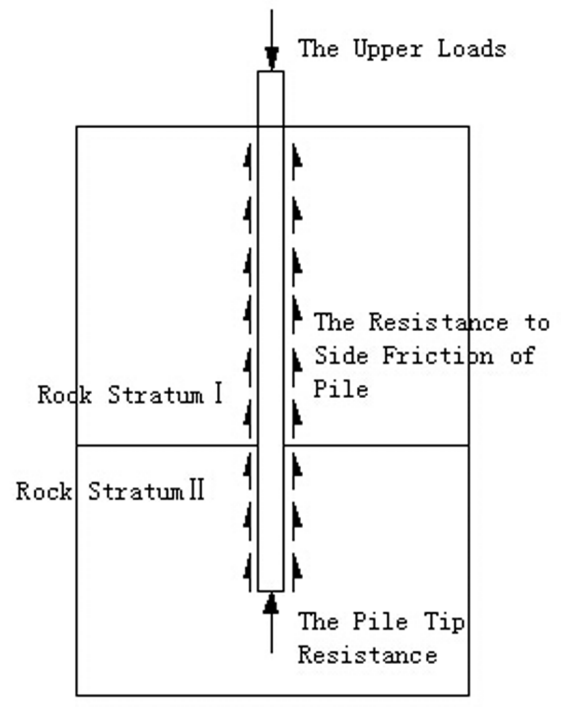

Fig. (1). The state of pile in ground stress.

In the latter mechanical mode, the state of pile stress transition changed from perfectly symmetry to non complete symmetry. And the effective length of pile foundation become shorter. On the one hand, making that the side friction of pile significantly decrease, on the other hand, it increasing the pile side thrust from the rock slope itself, all the above it formed the combined loads, which may made a certain of effect in pile foundation force balance and internal force distribution (Fig. (2)).

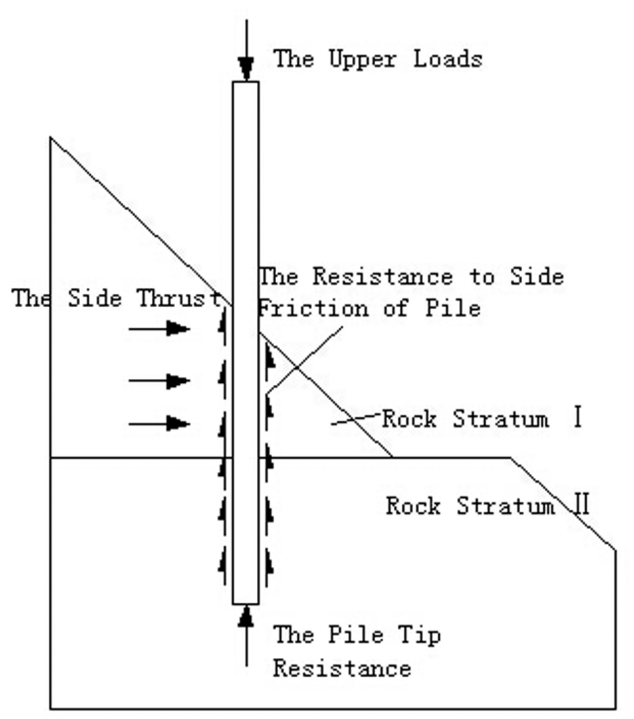

Fig. (2). The state of pile in high and steep slope.

\section{FINITE ELEMENT ANALYSIS ON PILE FOUNDA- TION IN HIGH AND STEEP SLOPE}

\subsection{Model of Numerical Analysis}

This paper only make single model calculating to the bridge pile foundation in high and steep rock slope in this paper. Combined with the related reference [8] and mechanical characteristics of single pile, made a number of spread- sheet, then the analysis model was determined. The model shape is that: 60 meters long, 50 meters high, and the angle of slope is $60^{\circ}$, the pile body is located in the two layers (above rock layer I and below rock layer II ), layer I is 22 meters thickness and layer II is 28 meters thickness.

\subsection{The Fundamental Assumptions}

In order to simplify the calculation and easy comparison, the analysis model was hypothesized as fellows:

(1) The material of pile body and the soil (rock) around the pile are homogeneous isotropic;

(2) The pile body is an ideal elastic material;

(3) Among the compute, the changing of water level and influence of seepage is not considered.

(4) When changing the related calculation parameters of pile, didn't consider the changing of its quality;

(5) When a single calculation parameter changes in the numerical modeling process, other parameters were kept constant.

\subsection{The Calculation Parameters}

In the calculation model, setting the pile body as linear elastic constitutive model, the soil (rock) was MohrCoulomb model, which can well describe the nonlinear characteristic of the soil (rock), to analysis the deformation characteristics of pile foundation under stress. The calculation parameters are shown in Table $\mathbf{1}$.

Table 1. The material parameters of finite element calculation.

\begin{tabular}{|c|c|c|c|c|c|}
\hline Material & $\begin{array}{c}E \\
/(\mathrm{kPa})\end{array}$ & $v$ & $\begin{array}{c}c \\
/(\mathrm{kPa})\end{array}$ & $\begin{array}{c}\varphi \\
/\left({ }^{\circ}\right)\end{array}$ & $\begin{array}{c}\gamma \\
/\left(\mathrm{N} / \mathrm{m}^{3}\right)\end{array}$ \\
\hline \hline $\begin{array}{c}\text { Concrete of Pile } \\
\text { Body }\end{array}$ & $3 \times 10^{7}$ & 0.20 & - & - & 24 \\
\hline Rock Stratum I & $4.5 \times 10^{5}$ & 0.30 & $8.0 \times 10^{2}$ & 20 & 18 \\
\hline Rock Stratum II & $2.8 \times 10^{7}$ & 0.25 & $2.7 \times 10^{3}$ & 25 & 23 \\
\hline
\end{tabular}

The principles of numerical modeling are that:

(1) Remaining the vertical pressure of loading on pile top $(p)$ constant, the load acting on rock slope top $(\varsigma)$ changed with levels, analysis the force of pile body and the distribution of pile side pressure along the pile direction.

(2) Keeping the load acting on rock slope $(\varsigma)$ unchanged, and changing the value of the vertical pressure $(p)$, analysis the change of pile's force and horizontal displacement of pile top.

The analysis model is shown in Fig. (3).

\section{RESULTS AND ANALYSIS}

Using the finite element modeling calculation, draw the corresponding variations of internal force, displacement and 
earth pressure contour. Due to the limited space, this paper only lists a few calculation results, as shown in Fig. (4).

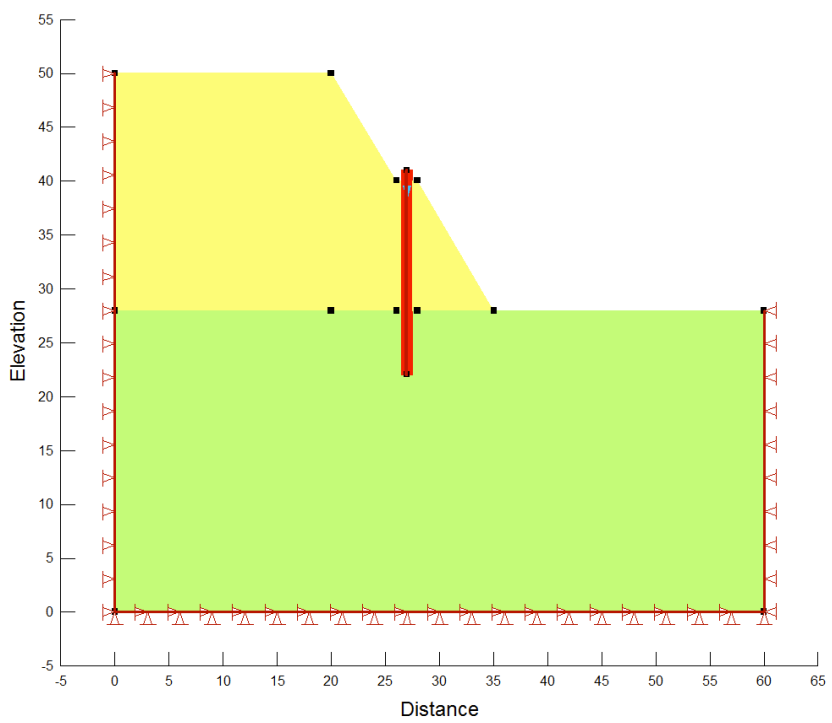

Fig. (3). The finite element analysis model.

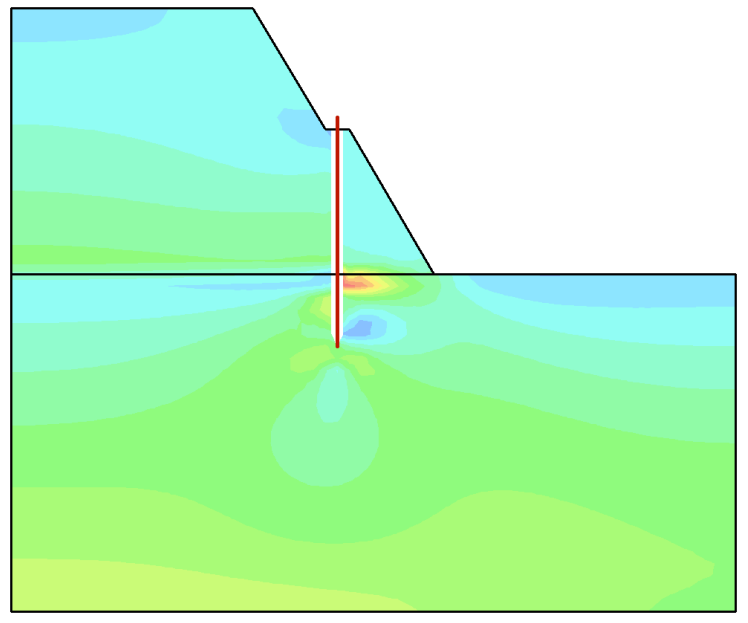

Fig. (4). The contour of calculation stress.

\subsection{The Change of Pile Internal Force Distribution}

Simulated three kinds of loading condition: first, the vertical loading on the top of pile $\mathrm{P}=0 \mathrm{kN}$, loading on the top of slope $Q=50 \mathrm{kN} / \mathrm{m}$; second, the vertical loading on the top of pile $\mathrm{P}=1000 \mathrm{kN}$, loading on the top of slope $Q=50 \mathrm{kN} / \mathrm{m}$; third, the vertical loading on the top of pile $\mathrm{P}=1000 \mathrm{kN}$, loading on the top of slope $\mathrm{Q}=0 \mathrm{kN}$. From the pile bending moment values of the respective length, obtained the pile bending moment distribution along the pile depth distribution in Fig. (5) under the condition of three different loading.

From Fig. (5):

(1) The internal force distribution of the bridge pile foundation that located in high steep rock slope is consistent with flattened piles. Without loading on the top of the pile, although there is lateral thrust, the top bending moment of the pile is zero. When the pile got forced from vertical direction, the pile bending moment reached a maximum value at the small range of burying depth, then the bending moment decreased sharply to zero and the reverse moment appeared, in the end gradually decayed to zero;

(2) When the pile suffered from the single loading (only the vertical loading on the top of pile or a stacking loading on the top of slope), the effect on pile internal force is slight. If the pile loading on the top of pile and the stacking loading on the top of slope were combined, the bending moment increased obviously, and have great effect on internal force.

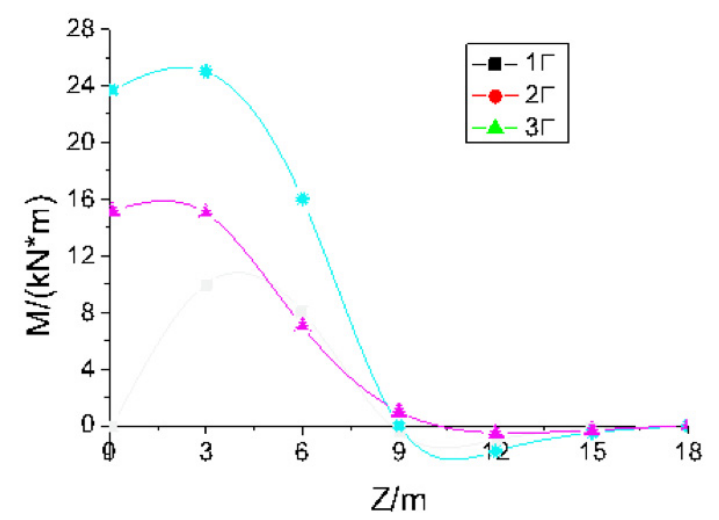

Fig. (5). The changes of pile bending moment diagram under different loading.

\subsection{Horizontal Displacements of Pile}

Applied vertical loading $\mathrm{P}=1000 \mathrm{kN}, 2000 \mathrm{kN}, 3000 \mathrm{kN}$, $4000 \mathrm{kN}, 5000 \mathrm{kN}, 6000 \mathrm{kN}$, under the circumstance of keeping each loading unchanged, extracted the maximum horizontal displacement and obtained the effect of combined loading on the change of horizontal displacements of pile which is shown in Fig. (6).

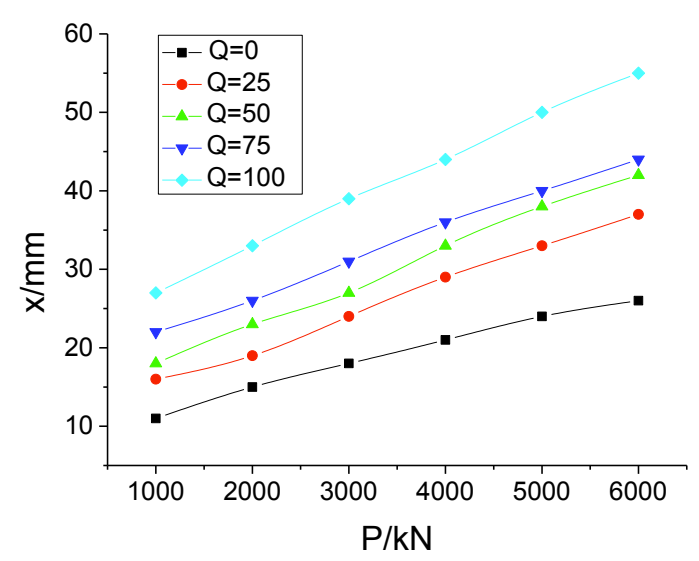

Fig. (6). The horizontal displacement of pile with different loading.

As shown in Fig. (6), compared with the effect of single loading, combined loading the effect on the horizontal dis- 
placement of the pile is greater. And the thrust produced by the side of the rock slope of pile effected the horizontal displacements obviously, with the load increased, even with small loading on the top of pile, would lead to large displacements. Therefore, the pile foundation construction that located in high and steep rock slope bridge, should be avoided in the rock slope side loading.

\subsection{The Landslide Section of Pile Lateral Soil Pressure Distribution}

During the modeling process, by changing the shape and rock material parameters, to set an imaginary potential sliding surface of rock slope. Over applying grade staking loading on the top of slope, extracted soil pressure values, drew the lateral thrust curve graphs which is shown in Fig. (7).

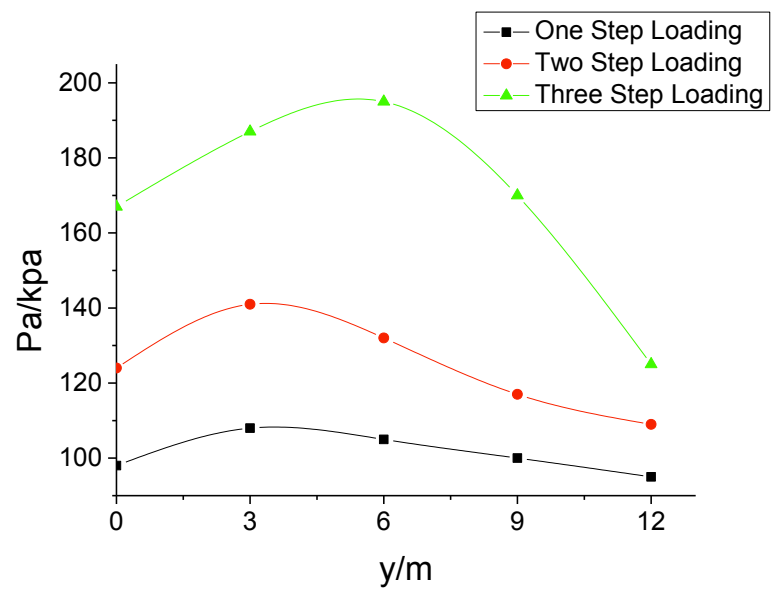

Fig. (7). The distribution of the slope lateral thrust.

From Fig. (7), the side thrust caused by landslide is approximately a parabola, which is consistent with the related research of conclusions and domestic scholars. Different levels of loading only change the force of the landslide thrust, and would not change the shape of the distribution.

\section{CONCLUSION}

Stress condition of pile foundation in high - steep slope rock is much more complex which not only bear the load acting on the pile, but also resist the lateral thrust from slope. This article based on the fruit of all the predecessors in high steep rock slope theoretical research and model experiment research that adopt finite element software to do the numerical analysis. The main conclusion are as following:

1. The regularities of distribution of internal force of pile foundation in high - steep rock slope and pile foundation in the flat are basically the same, but the special com- bined load effect that high - steep rock slope form is much disadvantage in stress and stability of pile foundation.

2. Compared with unique load effect, the combined load effect has much influence on pile displacement. Little load in one direction of high - steep rock slope can cause large displacement of pile foundation which top on them. Therefore, when constructing pile foundation in high steep rock slope, the load in one direction of high - steep rock slope should be avoided.

3. The side thrust act on pile foundation in high and steep rock slope can be considered as parabolic distribution, different levels of stack only change the value of landside thrust, can not change the distribution of thrust.

\section{CONFLICT OF INTEREST}

The authors confirm that this article content has no conflict of interest.

\section{ACKNOWLEDGEMENTS}

This work was financially supported by Open Fund of Key Laboratory of Bridge Engineering Safety Control by Hunan Province, Department of Education (Changsha University of Science \& Technology) (14KB06).

\section{REFERENCES}

[1] X. B. Gong, M. H. Yang, M. H. Zhao, P. B. Yin and X. W. Zhang, "Load-bearing mechanism model test for bridge pile foundation in high-steep transverse slope", China Journal of Highway and Transport, vol. 26, no. 2, pp. 56-62, 2013.

[2] M. H. Zhao, J. H. Liu and M. H. Yang, "Inner-force calculation of bridge pile foundation in high-steep rock slope under inclined loads", Chinese Journal of Rock Mechanics and Engineering, vol. 25, no. 11, pp. 2352-2357, 2006.

[3] M. H. Yang, M. H. Zhang, J. H. Liu and L. G. Wu, "Powerprogression solution for inner-force analysis of bridge pile in steep slope", Journal of Central South University (Science and Technology), vol. 38, no. 3, pp. 561-566, 2007.

[4] J. H. Liu, M. H. Zhao and L. G. Wu, "Stress analysis and model test study on the bridge piles in rock slope", Central South Highway Engineering, vol. 31, no. 4, pp. 25-29, 2006.

[5] J. H. Liu, M. H. Zhao and M. H. Yang, "Model tests on bridge pile foundation in high and steep rock slopes", Chinese Journal of Geotechnical Engineering, vol. 31, no. 3, pp. 372-377, 2009.

[6] M. H. Yang, G. X. Liu and M. H. Zhao, "Study on calculation method of bridge double piles structure in high-steep transverse slope", Journal of Highway and Transportation Research and Development, vol. 27, no. 8, pp. 55-60, 2010.

[7] P. F. Jiang, M. H. Yang, M. H. Zhao and S. Tang, "Study on socket length of bridge pile in steep slope section", Highway Engineering, vol. 32 , no. 5 , pp. 10-13, 2007.

[8] D. J. Chen, "Research on Vertical Load-Bearing Characteristics of the Large-Diameter Bridge Foundation", M.S. Thesis, Chang'an University, Xi'an, China, 2009.

\footnotetext{
Received: May 26, 2015

Revised: July 14, 2015

Accepted: August 10,2015

(C) Zhongming et al.; Licensee Bentham Open.
}

This is an open access article licensed under the terms of the (https://creativecommons.org/licenses/by/4.0/legalcode), which permits unrestricted, noncommercial use, distribution and reproduction in any medium, provided the work is properly cited. 